\title{
Suplementação de selênio quelatado na ração e qualidade da carne de frango
}

\section{Dietary supplementation of chelated selenium and broiler chicken meat quality}

\author{
Juliana Nunes de Almeida ${ }^{1}$; Gleice Rocha dos Santos ${ }^{1}$; \\ Flávia Maria Beteto ${ }^{2}$; Lara Gonçalves de Medeiros ${ }^{3}$; Alexandre $\mathrm{Oba}^{4}$; \\ Massami Shimokomaki ${ }^{5}$; Adriana Lourenço Soares ${ }^{6^{*}}$
}

\section{Resumo}

O selênio (Se) é componente da enzima glutationa peroxidase (GSH-Px) que catalisa a redução de peróxido de hidrogênio e peróxido lipídico, prevenindo danos oxidativos nos tecidos animais. A deficiência de Se aumenta a necessidade de vitamina E pelos animais. O objetivo deste trabalho foi avaliar o efeito da suplementação de selênio quelatado sobre a qualidade da carne de frango. Os 14 pintinhos de corte da linhagem Cobb de 1 dia de idade foram divididos em 2 grupos: C-Controle (sem suplementação) e S-Suplementado com 0,03mg Se quelatado. $\mathrm{kg}^{-1}$ de ração. Os frangos com 42 dias de idade foram abatidos e as sobrecoxas desossadas foram coletadas e armazenadas por 30 dias a $-18^{\circ} \mathrm{C}$. As sobrecoxas foram avaliadas quanto a perda por cozimento (PPC), oxidação lipídica pelo método de Substâncias Reativas ao Ácido Tiobarbitúrico (TBARS) e atividade da enzima GSH-Px pela oxidação do NADPH (Nicotinamida Adenina Dinucleotídeo Fosfato Reduzido). As sobrecoxas de frangos do grupo Suplementado perderam $33,8 \%$ menos de água após cozimento $(\mathrm{p} \leq 0,05)$ e apresentaram-se $23,6 \%$ menos oxidadas $(\mathrm{p} \leq 0,10)$ quando comparadas com as sobrecoxas do grupo Controle. A atividade da GSH-Px das sobrecoxas não diferiu significativamente $(p>0,05)$ entre os grupos Suplementado e Controle. A suplementação com $0,03 \mathrm{mg}$ de selênio quelatado por $\mathrm{kg}$ de ração promoveu melhora na qualidade da carne com redução na PPC e na oxidação lipídica, entretanto não aumentou a atividade da GSH-PX.

Palavras-chave: Oxidação lipídica, sobrecoxas de frango, perda de peso por cozimento

\begin{abstract}
The glutathione peroxidase (GSH-Px) is selenium-containing enzyme, which catalyses the reduction of hydrogen peroxides and lipid hydroperoxides preventing the oxidative damages in animal tissues. The selenium (Se) deficiency increases the need for vitamin E. The aim of this study was to investigate the effect of dietary supplementation of chelated Se on the poultry meat quality. Fourteen Cobb chicks with 1 day of age were divided into two groups: C-Control group (without supplementation) and S-Supplemented group (with $0.03 \mathrm{mg}$ of chelated Se. $\mathrm{kg}^{-1}$ of feed). Birds at 42 days of age were slaughtered and boneless skinless chicken thighs were collected and stored at $-18^{\circ} \mathrm{C}$ for 30 days. Thighs
\end{abstract}

\footnotetext{
${ }^{1}$ Discente(s) de Mestrado do Programa de Pós-graduação em Ciência de Alimentos da Universidade Estadual de Londrina, UEL, Londrina, PR. E-mail: juh.nunes@gmail.com; gleice_quimica@hotmail.com

${ }^{2}$ Discente em Farmácia, Bolsista de Iniciação Científica, UEL, Londrina, PR. E-mail:flaviabeteto@hotmail.com

${ }^{3}$ Discente de Mestrado do Programa de Pós-graduação em Ciência Animal, UEL, Londrina, PR. E-mail:laragmedeiros@hotmail.com

${ }^{4}$ Prof. Dr. do Dept ${ }^{\circ}$ de Zootecnia, Universidade Estadual de Londrina UEL, Londrina, PR. E-mail: oba@uel.br

${ }^{5}$ Prof. Dr. da Universidade Tecnológica Federal do Paraná, UTFPR, Campus Londrina, Londrina, PR. E-mail: mshimo@sercomtel. com.br

${ }^{6}$ Prof $^{\mathrm{a}} \mathrm{Dr}^{\mathrm{a}}$ do Dept ${ }^{\mathrm{o}}$ de Ciência e Tecnologia de Alimentos, UEL, Londrina, PR. E-mail: adri.soares@uel.br

* Autor para correspondência
} 
were analyzed for the cooking loss, lipid oxidation by Thiobarbituric-Acid-Reactive Substances (TBARS) and GSH-Px activity by coupled assay procedure recording the NADPH (nicotinamide adenine dinucleotide phosphate reduced) oxidation. Samples of Supplemented group presented $33.8 \%$ less water after cooking $(\mathrm{p} \leq 0.05)$ and were $23.6 \%(\mathrm{p} \leq 0.10)$ less oxidized when compared with samples of group Control. The GSH-Px activity of thighs did not differ significantly ( $\mathrm{p}>0.05$ ) between groups Supplemented and Control. The supplementation with $0.03 \mathrm{mg}$ of Se in the $\mathrm{kg}$ of feed improved the meat quality by reducing the lipid oxidation and cooking loss, however did not increase the GSH-Px activity.

Key words: Lipid oxidation, chicken thighs, cooking loss

\section{Introdução}

A qualidade sensorial e nutricional da carne é de grande importância no momento da escolha do consumidor. Sendo assim, a cadeia produtiva do frango de corte tem o desafio de oferecer cada vez mais produtos de qualidade, que apresentam boa suculência, maciez, cor e sabor agradáveis e que mantenham essas características por um longo período. Além de oferecer produtos seguros, isentos de contaminações microbiológicas e físico-químicas (OLIVO; SHIMOKOMAKI, 2002).

A oxidação lipídica das carnes é a principal causa da perda da qualidade de carnes e produtos cárneos. A rancidez inicia logo após a morte do animal envolve a formação de radicais livres que afetam a textura, sabor, cor e valor nutritivo da carne (SOARES et al., 2004, 2009). Os principais substratos envolvidos na oxidação são os ácidos graxos polinsaturados que compõem os fosfolipídios das membranas celulares e triacilgliceróis. A carne de frango por sua composição rica em ácidos graxos torna-se mais susceptível a sofrer processos oxidativos. Assim, o controle de processos oxidativos torna-se importante e a adição de vitaminas e minerais na ração dos animais tem sido uma alternativa necessária.

O selênio ( $\mathrm{Se}$ ) é um micromineral essencial e quando suplementado na ração dos animais tem demonstrado melhorar o desempenho e qualidade da carne de aves (BOIAGO, 2006), suínos (RUTZ; MURPHY, 2009) e bovinos (MAHAN; MOXON; HUBBARD, 1977). Os minerais orgânicos ou quelatados referem-se a minerais que estão complexados com substâncias orgânicas como aminoácidos ou peptídeos e que por isso apresentam-se mais biodisponíveis, sendo mais facilmente absorvidos e retidos pelo organismo animal, ao contrário dos inorgânicos (BRITO, 2005; SECHINATO; ALBUQUERQUE; NAKADA, 2006; RUTZ; MURPHY, 2009).

O Se é um componente importante da enzima GSH-Px, pois compõe seu sítio catalítico. A GSHPx atua sobre os peróxidos lipídicos e peróxidos de hidrogênio, convertendo-os em hidroxiácidos e água, a partir da glutationa reduzida (GHS). Nestas reações, duas moléculas de glutationa reduzida (GSH) são oxidadas à glutationa dissulfeto (GSSG) enquanto uma molécula de peróxido de hidrogênio ou peróxido lipídico é reduzida pela ação da GSH-Px, a glutationa oxidada (GSSG) pode ser regenerada através da redução pela glutationa redutase (HUBER; ALMEIDA; FÁTIMA, 2008).

O Se induz a biossíntese da selênio-enzima GSH-Px, que tem como função no organismo a ação antioxidante primária, além de proteger espécies que utilizam metabolismo oxidativo da ação de radicais livres. A atividade de GSH-Px é considerada como um indicador da localização de Se em uma variedade de espécies (GANTHER, 1979). A falta de selênio no organismo animal torna as células mais susceptíveis ao processo oxidativo, além de aumentar a necessidade de vitamina E (KOHRLE et al., 2000).

Assim, o objetivo deste trabalho foi avaliar o efeito da suplementação de Se quelatado sobre a qualidade da carne de frango. 


\section{Material e Métodos}

\section{Animais e tratamentos}

Os pintinhos de corte machos da linhagem Cobb de 1 dia de idade foram divididos em 2 grupos: C-Controle (sem suplementação) $(n=7)$ e S-Suplementado com $0,03 \mathrm{mg}$ Se quelatado. $\mathrm{kg}^{-1}$ de ração $(\mathrm{n}=7)$. Os frangos foram criados na Fazenda Escola da Universidade Estadual de Londrina, onde receberam água e alimento ad libitum durante todo o período experimental de 42 dias. As rações experimentais atenderam as exigências mínimas preconizadas por Rostagno et al. (2011) conforme descrito na Tabela 1. Após 42 dias as aves foram pesadas individualmente e de acordo com o peso médio foram selecionadas 7 frangos de cada tratamento para serem abatidos. Os frangos foram abatidos seguindo as práticas comerciais: insensibilização elétrica, sangria, escaldagem, depenagem, evisceração e chiller. A sobrecoxas foram desossadas e retiradas a pele e armazenadas por 30 dias $\mathrm{a}-18^{\circ} \mathrm{C}$. A pesquisa foi avaliada e aprovada pela Comissão de Ética no Uso de Animais da Universidade Estadual de Londrina (registro processo 29285.2011.84).

Tabela 1. Composição percentual e calculada das rações nas diferentes fases de criação de frangos de cortes criados até os 42 dias de idade.

\begin{tabular}{|c|c|c|c|c|}
\hline Ingredientes & Pré-Inicial & Inicial & Crescimento & Terminação \\
\hline Milho grão & 55,436 & 57,893 & 60,740 & 65,018 \\
\hline Soja farelo $45 \%$ & 38,013 & 35,151 & 31,580 & 27,683 \\
\hline Óleo de soja & 2,307 & 3,187 & 4,063 & 3,987 \\
\hline Fosfato bicálcico & 1,931 & 1,575 & 1,344 & 1,120 \\
\hline Calcário & 0,788 & 0,835 & 0,796 & 0,722 \\
\hline Sal comum & 0,507 & 0,482 & 0,457 & 0,445 \\
\hline Premix vit. mineral ${ }^{1}$ & 0,400 & 0,400 & 0,400 & 0,400 \\
\hline L-Lisina $\mathrm{HCl}$ & 0,308 & 0,257 & 0,256 & 0,281 \\
\hline Dl-Metionina & 0,184 & 0,129 & 0,281 & 0,257 \\
\hline L-Treonina & 0,126 & 0,091 & 0,083 & 0,087 \\
\hline Total & 100 & 100 & 100 & 100 \\
\hline \multicolumn{5}{|l|}{ Calculada } \\
\hline Energia metabolizável (kcal/kg) & 2960 & 3050 & 3150 & 3200 \\
\hline Proteina bruta $(\%)$ & 21,050 & 20,240 & 19,040 & 17,810 \\
\hline Metionina digestível (\%) & 0,519 & 0,449 & 0,408 & 0,376 \\
\hline Met. + cist. digestível (\%) & 0,994 & 0,817 & 0,734 & 0,676 \\
\hline Lisina digestível (\%) & 1,330 & 1,151 & 1,020 & 0,939 \\
\hline Treonina digestível (\%) & 0,865 & 0,748 & 0,663 & 0,610 \\
\hline Selênio (\%) & 0,0037 & 0,0033 & 0,0030 & 0,0023 \\
\hline Cálcio (\%) & 0,894 & 0,853 & 0,794 & 0,735 \\
\hline Fósforo disponível (\%) & 0,450 & 0,428 & 0,398 & 0,367 \\
\hline
\end{tabular}

${ }^{1}$ Pré-Inicial e Inicial: vit. A 2750 UI/g, vit. D3 550 UI/g, vit. K3 419,900 mg/kg, vit. B1 380,158 mg/kg, vit. B2 1250 mg/kg, vit. B6 600,188 mg/ $\mathrm{kg}$, vit. B12 $4000 \mathrm{mcg} / \mathrm{kg}$, vit. E 8750 UI, pantotenato de cálcio $3000 \mathrm{mg} / \mathrm{kg}$, niacina $8750 \mathrm{mg} / \mathrm{kg}$, ácido fólico $175 \mathrm{mg} / \mathrm{kg}$, biotina $17 \mathrm{mg} / \mathrm{kg}$, colina $65000 \mathrm{mg} / \mathrm{kg}$, metionina $419999 \mathrm{mg} / \mathrm{kg}$, zinco $12500 \mathrm{mg} / \mathrm{kg}$, ferro $12500 \mathrm{mg} / \mathrm{kg}$, cobre $3000 \mathrm{mg} / \mathrm{kg}$, manganês $15000 \mathrm{mg} / \mathrm{kg}$, iodo $250,067 \mathrm{mg} / \mathrm{kg}$, selênio $93,750 \mathrm{mg} / \mathrm{kg}$, cobalto $50 \mathrm{mg} / \mathrm{kg}$, antioxidante $1000 \mathrm{mg} / \mathrm{kg}$, coccidiostático $125000 \mathrm{mg} / \mathrm{kg}$, promot. cresc. gran negativo $6250 \mathrm{mg} / \mathrm{kg}$, promot. cresc. gran positivo $125000 \mathrm{mg} / \mathrm{kg}$. Crescimento: vit. A $2250 \mathrm{UI} / \mathrm{g}$, vit. D3 $450 \mathrm{UI} / \mathrm{g}$, vit. K3 417,950 mg/kg, vit. B1 300,125 mg/kg, vit. B2 1000 mg/ $\mathrm{kg}$, vit. B6 450,038 mg/kg, vit. B12 $3000 \mathrm{mcg} / \mathrm{kg}$, vit. E 7000 UI, pantotenato de cálcio 2500,083 mg/kg, niacina 7000,058 mg/kg, ácido fólico 140 $\mathrm{mg} / \mathrm{kg}$, biotina $14 \mathrm{mg} / \mathrm{kg}$, colina $55000 \mathrm{mg} / \mathrm{kg}$, metionina $379999,531 \mathrm{mg} / \mathrm{kg}$, zinco $12500 \mathrm{mg} / \mathrm{kg}$, ferro $12500 \mathrm{mg} / \mathrm{kg}$, cobre $3000 \mathrm{mg} / \mathrm{kg}$, manganês $14999,996 \mathrm{mg} / \mathrm{kg}$, iodo $250 \mathrm{mg} / \mathrm{kg}$, selênio $75 \mathrm{mg} / \mathrm{kg}$, cobalto $50 \mathrm{mg} / \mathrm{kg}$, antioxidante $1000 \mathrm{mg} / \mathrm{kg}$, coccidiostático $125000 \mathrm{mg} / \mathrm{kg}$, promot. cresc. gran negativo $6250 \mathrm{mg} / \mathrm{kg}$, promot. cresc. gran positivo $125000 \mathrm{mg} / \mathrm{kg}$. Acabamento: vit. A $1000 \mathrm{UI} / \mathrm{g}$, vit. D3 $200 \mathrm{UI} / \mathrm{g}$, vit. K3 180,050 mg/kg, vit. B1 $149,858 \mathrm{mg} / \mathrm{kg}$, vit. B2 $500 \mathrm{mg} / \mathrm{kg}$, vit. B6 249,975 mg/kg, vit. B12 $1250 \mathrm{mcg} / \mathrm{kg}$, vit. E 3500 UI, pantotenato de cálcio $1200,167 \mathrm{mg} / \mathrm{kg}$, niacina 70 $\mathrm{mg} / \mathrm{kg}$, ácido fólico $70 \mathrm{mg} / \mathrm{kg}$, biotina $7 \mathrm{mg} / \mathrm{kg}$, colina $45000 \mathrm{mg} / \mathrm{kg}$, metionina 300000,125 mg/kg, zinco $12500 \mathrm{mg} / \mathrm{kg}$, ferro $12500 \mathrm{mg} / \mathrm{kg}$, cobre $3000 \mathrm{mg} / \mathrm{kg}$, manganês $15000 \mathrm{mg} / \mathrm{kg}$, iodo $250,067 \mathrm{mg} / \mathrm{kg}$, selênio $56,250 \mathrm{mg} / \mathrm{kg}$, cobalto $50 \mathrm{mg} / \mathrm{kg}$, antioxidante $1000 \mathrm{mg} / \mathrm{kg}$.

Fonte: Rostagno et al. (2011). 
Perda de peso por cozimento (PPC)

A PPC foi determinada de acordo com metodologia descrita por Honikel (1998). As sobrecoxas desossadas foram pesadas, acondicionadas em sacos plásticos hermeticamente fechados e, em seguida, cozidas em banho-maria a $90^{\circ} \mathrm{C}$ até atingirem temperatura interna de $75 \pm 5^{\circ} \mathrm{C}$. Após o cozimento a água exsudada foi desprezada, e as amostras resfriadas até a temperatura ambiente e novamente pesadas. A PPC foi expressa em percentagem calculada pela diferença de peso da amostra.

\section{Oxidação lipídica}

A oxidação lipídica foi determinada pelo método de substâncias reativas ao ácido tiobarbitúrico (TBARS) conforme procedimento descrito por Tarladgis, Pearson e Dugan (1964). Neste procedimento, $10 \mathrm{~g}$ de amostra foram homogeneizadas com $98 \mathrm{~mL}$ de água destilada, 2,5 $\mathrm{mL}$ de $\mathrm{HCl} 4$ mol.L ${ }^{-1}, 2$ gotas de antiespumante e algumas pérolas de vidro. A solução foi destilada durante 10 minutos e o destilado coletado. Em uma alíquota de $5 \mathrm{~mL}$ do destilado foram adicionados 5 $\mathrm{mL}$ de ácido tiobarbitúrico (TBA) 0,02 mol.L-1, e colocados em banho-maria fervente por 35 minutos, resfriados e realizada leitura em espectrofotômetro a $530 \mathrm{~nm}$. Uma curva padrão foi construída utilizando solução de 1,1,3,3-tetraetoxipropano em água destilada, nas concentrações de 0,7 a 2,0 mol.L-1 ${ }^{-1}$ Os resultados foram expressos em mg de TBARS. $\mathrm{kg}^{-1}$ de amostra. O método apresentou uma recuperação de $81 \%$.

\section{Atividade glutationa peroxidase (GSH-Px)}

A atividade da GSH-Px foi realizada através da medida de oxidação do NADPH, acompanhada pela diminuição da absorvância a $340 \mathrm{~nm}$ (CHEN; LINDMARK-MANSSON; AKESSON, 2000). $5,0 \mathrm{~g}$ de amostra foram homogeneizadas com tampão fosfato 0,25 mol. $\mathrm{L}^{-1}(\mathrm{pH}=7,6)$ em ultra- turrax em velocidade máxima em banho de gelo, sendo posteriormente centrifugadas por 20 minutos a $10.000 \mathrm{~g}$ e filtradas. Uma alíquota de $100 \mu \mathrm{L}$ do filtrado reagiu com $200 \mu \mathrm{L}$ de tampão fosfato $\mathrm{pH}$ 7,4 e 25 mmol. $\mathrm{L}^{-1}$ de EDTA, 11,1 $\mu \mathrm{L}$ de glutationa redutase $(5 \mathrm{U})$ e $50 \mu \mathrm{L}$ de glutaiona reduzida (40 mmol. $\mathrm{L}^{-1}$ ) e foram incubados por 10 minutos a $37^{\circ} \mathrm{C}$. Em seguida, $10 \mu \mathrm{L}$ de $20 \mathrm{mmol}^{-\mathrm{L}^{-1}}$ de NADPH e 620 $\mu \mathrm{L}$ de tampão fosfato $\mathrm{pH} 7,4$ foram adicionados. A reação iniciou-se pela adição $20 \mu \mathrm{L}$ de 15 mmol.L ${ }^{-1}$ de terc-butilhidroperóxido e a absorvância foi acompanhada por 5 minutos, em intervalos de 1 minuto. Um branco foi preparado sem a adição de GSH-Px. A atividade de GSH-Px foi expressa em 1

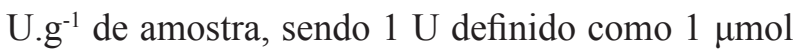
de NADPH oxidado. min $^{-1}$.

\section{Quantidade de selênio na carne}

A quantidade de selênio foi determinada conforme procedimento descrito por Daun et al. (2001). As amostras foram digeridas com ácido perclórico e ácido nítrico, reduzidas à selenito com ácido clorídrico concentrado e o conteúdo de selênio determinado por espectrofotômetro de absorção atômico utilizando forno de grafite com geração de hidreto.

\section{Análise estatística}

O teste $t$-Student a $5 \%$ e $10 \%$ de probabilidade foi aplicado para comparação dos resultados entre os grupos C-Controle e S-Suplementado utilizando o programa STATISTICA for Windows versão 7.0.

\section{Resultados e Discussão}

A Tabela 2 apresenta os resultados de Perda de peso por cozimento (PPC), oxidação lipídica, atividade da glutationa peroxidase (GSH-Px) e conteúdo de selênio das sobrecoxas de frangos dos grupos C-Controle (sem suplementação) e S-Suplementado com $0,03 \mathrm{mg}$ de Se quelatado. 
$\mathrm{kg}^{-1}$ de ração. A PPC foi significativamente menor $(\mathrm{p} \leq 0,05)$ para as sobrecoxas de frango do grupo Suplementado quando comparadas com as amostras do grupo Controle, indicando melhora da capacidade de retenção de água nas carnes com a suplementação de Se, resultado semelhante foi obtido por outros autores (EDENS, 1996). Boiago (2006) observou que filés de peito de frango suplementados com Se nas concentrações de 0,3 e 0,5 mg. $\mathrm{kg}^{-1}$ de ração apresentaram menor luminosidade e maior
$\mathrm{pH}$. Filés de frango com valores de $\mathrm{pH}$ baixos e alta luminosidade são caracterizados como carnes PSE (Pale, Soft e Exudative) e apresentam baixa capacidade de retenção de água devido a desnaturação de proteínas face a rápida glicólise post-mortem (OLIVO et al., 2001). Além disso, quanto maior o $\mathrm{pH}$ da carne mais distante está do ponto isoelétrio das proteínas musculares que é próximo a 5,4 aumentando a capacidade da proteína de reter água.

Tabela 2. Perda de peso por cozimento (PPC), oxidação lipídica, atividade da glutationa peroxidase (GSH-Px) e conteúdo de selênio de sobrecoxas de frangos dos grupos C-Controle (sem suplementação) e S-Suplementado com $0,03 \mathrm{mg}$ de Se quelatado $\cdot \mathrm{kg}^{-1}$ de ração.

\begin{tabular}{lcc}
\hline & C-Controle & S-Suplementado \\
\hline PPC (\%) & $24,70^{\mathrm{A}} \pm 1,92$ & $16,34^{\mathrm{B}} \pm 1,78$ \\
Oxidação Lipídica (mg TBARS.kg-1 de amostra) & $0,072^{\mathrm{a}} \pm 0,016$ & $0,054^{\mathrm{b}} \pm 0,018$ \\
GSH-Px (U.g ${ }^{-1}$ de amostra) & $0,41^{\mathrm{a}} \pm 0,21$ & $0,26^{\mathrm{a}} \pm 0,06$ \\
Selênio & $0,63^{\mathrm{a}} \pm 0,07$ & $0,58^{\mathrm{a}} \pm 0,04$ \\
\hline
\end{tabular}

${ }^{\text {A-B }}$ Médias seguidas de letras maiúsculas diferentes na mesma coluna diferem entre si pelo teste $t$ de Student a 5,0\% de probabilidade $(\mathrm{p} \leq 0,05)$.

${ }^{\mathrm{a}-\mathrm{b}}$ Médias seguidas de letras minúsculas diferentes na mesma coluna diferem entre si pelo teste $t$ de Student a $10,0 \%$ de probabilidade $(\mathrm{p} \leq 0,10)$.

Fonte: Elaboração dos autores.

As sobrecoxas de frango do grupo Controle apresentaram valores de oxidação lipídica significativamente maiores $(p \leq 0,10)$ em relação às sobrecoxas de frango do grupo Suplementado, demonstrando que a adição de Se orgânico na ração previne a oxidação lipídica das carnes. Boiago (2006) também verificou que filés de frango suplementados com Se nas concentrações de 0,3 e $0,5 \mathrm{mg} \cdot \mathrm{kg}^{-1}$ apresentaram menor oxidação lipídica que filés Controle. Wang et al. (2009) relataram que a suplementação com 0,3 e 0,6 mg Se quelatada. $\mathrm{kg}^{-1}$ reduziu o conteúdo de malonaldeído na carne.

A atividade da GSH-Px das sobrecoxas não diferiu significativamente $(\mathrm{p}>0,05)$ entre os grupos Suplementado e Contole apesar da menor oxidação lipídica observada nas sobrecoxas de frango do grupo S. Isto ocorreu porque o conteúdo de Se depositado nas sobrecoxas também não diferiu significativamente $(p<0,05)$ entre as amostras do grupo Suplementado e do grupo Controle. O nível de suplementação utilizada neste experimento foi baixa, não sendo suficiente para aumentar a atividade da GSH-Px. Apesar da atividade da enzima antioxidante GSH-Px não ter aumentado no grupo Suplementado observou-se que as sobrecoxas apresentaram-se $23,6 \%$ menos oxidadas $(p \leq 0,10)$ que do grupo Controle.

\section{Conclusão}

A suplementação com $0,03 \mathrm{mg}$ de selênio quelatado na ração promoveu melhora na qualidade da carne com redução na perda de peso por cozimento e na oxidação lipídica, entretanto não aumentou a atividade da GSH-PX. 


\section{Agradecimentos}

À Coordenação de Aperfeiçoamento de Pessoal de Nível Superior/CAPES/MEC pela bolsa de Mestrado.

\section{Referências}

BOIAGO, M. M. Características produtivas $e$ qualitativas da carne de frangos alimentados com diferentes concentrações e fontes de selênio. 2006. Dissertação (Mestrado em Zootecnia) - Universidade Estadual Paulista, Jaboticabal.

BRITO, J. A. G. Uso de microminerais sob a forma de complexo orgânico em rações de frangas na fase de recria. 2005. Dissertação (Mestrado em Zootecnia) Universidade Federal de Lavras, Lavras.

CHEN, J.; LINDMARK-MANSSON, H.; AKESSON, B. Optimisation of a coupled enzymatic assay of glutathione peroxidase activity in bovine milk and whey. International Dairy Journal, Barking, v. 10, n. 5-6, p. 347-352, 2000.

DAUN, C.; JOHANSSON, M.; ÖNNING, G.; AKESSON, B. Glutathione peroxidase activity, tissue and soluble selenium content in beef and pork in relation to meat ageing and pig RN phenotype. Food Chemistry, London, v. 72, n. 3, p. 313-319, 2001.

EDENS, F. W. Sodium selenite versus selenium yeast in diets fed broilers: effects on performance, feathering, meat quality and yields. In: ANNUAL SYMPOSIUM OF BIOTECHNOLOGY IN THE FEED AND FOOD INDUSTRIES, 1996, 12., Kentuky. Anais...Kentuky: [s.n], 1996. Pôster.

GANTHER, H. E. Metabolism of hydrogen selenide and methylated selenides. Advances in Nutrition Research, New York, v. 2, p. 107-128, 1979.

HONIKEL, K. O. Reference methods for the assessment of physical characteristics of meat. Meat Science, Barking, v. 49, n. 4, p. 447-457, 1998.

HUBER, P. C.; ALMEIDA, W. P.; FÁTIMA, A. Glutationa e enzimas relacionadas: papel biológico e importância em processos patológicos. Química Nova, São Paulo, v. 31, n. 5, p. 1170-1179, 2008.

KOHRLE, J.; BRIGELIUS-FLOHÉ, R.; BÖCK, A.; GÄRTNER, R.; MEYER, O.; FLOHÉ, L. Selenium in biology: facts and medical perspectives. Biological Chemistry, Salt Lake, v. 381, n. 9-10, p. 849-864, 2000.

MAHAN, D. C.; MOXON, A. L.; HUBBARD, M. Efficacy of inorganic selenium supplementation to cow diets on resulting carry-over to their progeny. Journal of Animal Science, Madison, v. 45, n. 9, p. 738-746, 1977.

OLIVO, R.; SHIMOKOMAKI, M. Carnes: no caminho da pesquisa. 2. ed. Cocal do Sul, SC: IMPRINT, 2002, $155 \mathrm{p}$.

OLIVO, R.; SOARES, A. L.; IDA, E. I.; SHIMOKOMAKI, M. Dietary vitamin E inhibits poultry PSE and improves meat functional properties. Journal of Food Biochemistry, Trumbull, v. 25, n. 4, p. 271-283, 2001.

ROSTAGNO, H. S.; ALBINO, L. F. T.; DONZELE, J. L.; GOMES, P. C.; OLIVEIRA, R. F. de; LOPES, D. C.; FERREIRA, A. S.; BARRETO, S. L. de T. Tabelas brasileiras para aves e suinos: composição de alimentos e exigências nutricionais. 3. ed. Viçosa, MG: UFV, DZO, 2011. $252 \mathrm{p}$.

RUTZ, F.; MURPHY, R. Minerais orgânicos para aves e suínos. In: CONGRESSO INTERNACIONAL SOBRE USO DA LEVEDURA NA ALIMENTAÇÃO ANIMAL CBNA, 1., 2009, Campinas. Anais... Campinas: CBNA, 2009, p. 20.

SECHINATO, A. S.; ALBUQUERQUE, R.; NAKADA, S. Efeito da suplementação dietética com micros minerais orgânicos na produção de galinhas poedeiras. Brazilian Journal of Veterinary Research and Animal Science, São Paulo, v. 43, n. 2, p. 159-166, 2006.

SOARES, A. L.; OLIVO, R.; SHIMOKOMAKI, M.; IDA, E. I. Synergism between dietary vitamin E and exogenous phytic acid in prevention of warmed-over flavour development in chicken breast meat, Pectoralis major M. Brazilian Archives of Biology and Technology, Curitiba, v. 47, n. 1, p. 57-62, 2004.

SOARES, A. L.; MARCHI, D. F.; MATSUSHITA, M.; GUARNIERI, P. D.; DROVAL, A. A.; IDA, E. I.; SHIMOKOMAKI, M. lipid oxidation and fatty acid profile related to broiler breast meat color abnormalities. Brazilian Archives of Biology and Technology, Curitiba, v. 52, n. 6, p. 1513-1518, 2009.

TARLADGIS, B. G.; PEARSON, A. M.; DUGAN, R. Chemistry of the 2-thiobarbituric test for determination of oxidative rancidity in foods. II formation of the TBAmalonaldehyde complex without acid-heat treatment. Journal of Food Science and Agriculture, London, v. 5, n. 6, p. 602-604, 1964.

WANG, Z. G.; PAN, X. J.; PENG, Z. Q.; ZHAO, R. Q.; ZHOU, G. H. Methionine and selenium yeart supplementation of the maternal diets affects color, water-holding capacity, and oxidative stability of their male offspring meat at the early stage. Journal of Poultry Science, Honduras, v. 88, n. 5, p. 1096-1101, 2009. 